ESTUDOS LINGÜÍSTICOS 


\section{ENSINO DO PORTUGUÊS COMO SEGUNDA LÍNGUA: QUE FAZER?}

Elena Godoy ${ }^{*}$

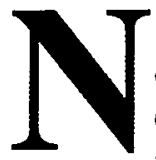

o contexto presente, em que os tratados econômicos são assinados entre vários países da América Latina, vemos que os termos em alta, as palavras de ordem que estão na boca de todos e povoam as manchetes dos meios de comunicação são globalização e integração.

Diante desta realidade, inserida num contexto maior de transformações, onde o movimento da globalização dialoga com o de fragmentação, em todos os níveis, os professores de espanhol e de português como segundas línguas se vêem colocados diante de uma tarefa gigantesca e urgente. Mas, apesar desta urgência, precisamos refletir. E também precisamos conjugar a reflexão com a imperiosa necessidade de obter bons resultados. $E$ logo. É o momento muito propício ao delineamento de questões de suma importância, se formos profissionais conscientes e preocupados em encontrar ou criar novos caminhos que levem a uma melhor "performance" do professor e do aluno, tendo como "produto final acabado" (para usar a terminologia fartamente utilizada nos tratados a que aludimos no começo), o bom domínio, pelos nossos alunos, das línguas em jogo na qualidade de segundas. É inadiável a formação adequada e rápida de professores de língua portuguesa para estrangeiros em geral e, em especial, para hispanofalantes. É o momento de olharmos de frente para o fato

* Universidade Federal do Paraná. 
de que aprender português, para um estudante hispanofalante, é diferente do que pode ser para um americano, um chinês ou um alemão, da mesma forma que é diferente para um brasileiro aprender espanhol e não o inglês, ou russo, ou japonês.

Sabemos pela experiência que, no Brasil, um (bom) professor de português formado num (bom) curso de Letras/Português com aquele (bom) curriculum, que esse curso normalmente tem, "apanha" bastante quando resolve trabalhar com o ensino de português para estrangeiros. Salvam-se os que têm maior intuição lingüística, maior flexibilidade cultural e, de preferência, algum conhecimento de alguma língua estrangeira. Em outras palavras: bons artesãos.

Nesta situação, parece óbvia a necessidade e a urgência de buscar a resolução das tarefas que se impõem, conferindo-lhes qualidade acadêmica. Por qualidade acadêmica entendemos que todos os trabalhos a serem desenvolvidos, seja referentes à elaboração de conteúdos programáticos, metodologia de ensino, materiais didáticos, capacitação de professores ou outros trabalhos que possam vir a ser necessários, devem ser resultado de pesquisas sérias, bem como da experiência e conhecimento docente dos professores de espanhol e português.

Entendemos por professor preparado o professor que tem consciência lingüística da língua que está ensinando e da língua materna dos seus alunos e que, portanto, conhece a estrutura e o funcionamento de ambas as línguas. Por outro lado, para que o ensino seja realmente eficaz, os materiais didáticos também devem ser específicos, levando em conta a língua materna do públicoalvo. Essas exigências tornam-se imperativas no caso de ensino de línguas tão próximas tipologicamente como o espanhol e o português, que têm estruturas semelhantes, o que cria a sensação de extrema facilidade de ensinar e de aprender e leva aos resultados tristemente conhecidos: o portunhol e, se quiserem, o espaguês como o outro lado da medalha. Portanto, tudo que acabamos de dizer e o que será dito adiante vale também para este "outro lado da medalha", isto é, o ensino de espanhol para brasileiros.

Não queremos dizer com isso que o ensino/aprendizagem do português/ $L_{2}$ para hispanofalantes seja uma tarefa monstruosamente difícil. Mas precisamos, mais uma vez, refletir por que, sendo as duas línguas tão próximas, os resultados normalmente ficam tão longe dos almejados e o aluno "fossiliza" sua interlíngua tão rapidamente depois da curta "euforia" da facilidade e velocidade da aprendizagem no período inicial.

Quando se trata do ensino/aprendizagem de línguas, lidamos com várias coisas próximas e, no entanto diferentes. Buscamos um bom desempenho do aluno, ou seja, queremos sua proficiência comunicativa. Mas, por trás dessa proficiência se encontra a competência comunicativa, que inclui vários componentes, inclusive, e em primeiro lugar, o lingúístico (cf. Canale, 1983). Na 
literatura da área, se discute acaloradamente sobre a natureza do conhecimento que subjaz à competência: é inato? até que ponto? é adquirido? em que medida? baseado em que? A revisão crítica desses conceitos e das discussões que eles suscitam seria assunto para outro trabalho. Aqui, assumiremos que há conhecimento lingüístico universal inato, como há base universal das formações culturais específicas, havendo também lugar para aquisição individual da competência.

Sendo o espanhol e o português duas línguas tipologicamente próximas, compartilham uma porção da gramática universal e todos os princípios que disso decorrem e entram juntas na mesma variante paramétrica (o parâmetro pro-drop, por exemplo, também com todas as consequiências da parametrização). Isso, junto com as semelhanças do léxico, em boa parte comum - historicamente -, o aluno descobre em pouco tempo. Restam as chamadas "regras marcadas", que não pertencem ao núcleo da gramática, mas a sua periferia, e são elas que se transferem (negativamente) para a interlíngua que deixa de ter regras em competição. Ocorre a "fossilização" baseada fundamentalmente na overgeneralization interlingüística. Isto é, na interlíngua, se projetam mais regras (marcadas) da $\mathrm{L}_{1}$, porque o aprendiz fica com a sensação de que tudo "é a mesma coisa". Como exemplos, vamos encontrar as formas do futuro analítico com a preposição, do tipo vamos a encontrar (e não vamos encontrar da nossa frase), a posição do pronome clítico antes do verbo auxiliar: te vou a mostrar em vez de vou te mostrar, ou, então, com o clítico posposto ao infinitivo (também como em espanhol e também como é e por isso "fica com cara" do português peninsular): vou a mostrar-te, etc., etc.

Dissemos que as duas línguas são tipologicamente próximas, usando aqui o conceito de distância no sentido de fenômeno lingüístico, o grau de diferenças entre as línguas. Entretanto, existe também o conceito psicolingüístico de distância, que traduz o que os aprendizes pensam que é a diferença e, após o período inicial da aprendizagem, esta distância diminui e as diferenças tendem a se apagar (justamente devido à sensação de que tudo "é a mesma coisa"), fundamentando a "fossilização precoce". Essa "fossilização" rápida, que tanto mencionamos, se deve também a alguns outros fatores. A pressão comunicativa, ou seja, a necessidade de comunicar idéias, que tanto se deseja e se exige na abordagem comunicativa de ensino, e a aparente facilidade, no caso das duas línguas tão próximas, excedem a competência lingüística, mas o feedback positivo (este "Te entendo, continua", explícito ou implícito, por parte do interlocutor) não estimula a reelaboração de hipóteses e regras. Com o que dissemos, parece claro que a aquisição do português pelos hispanofalantes é, na maioria dos casos, mas evidentemente não em todos, a criação de representações mentais não analisadas. Ou seja, no caso do ensino de uma segunda língua 
tipologicamente muito próxima da materna, a própria ênfase na comunicação (esta entendida de maneira ingênua, como muitas vezes acontece) pode se tornar traiçoeira.

Já foi mostrado pelos pesquisadores (por exemplo, Spada, 1986) que os aprendizes que têm a exposição à língua e recebem a instrução formal (o ensino da gramática e de outras regras que fazem parte da competência comunicativa) se tornam mais proficientes e seu progresso é mais rápido. Pica $(1983,1985)$ adverte, entretanto, que o ensino parece inibir (não prevenir) o uso de construções agramaticais, mas comunicativamente eficazes, do tipo pidgin. Kadia (1988) nota que o ensino da gramática tem mais efeitos sobre a produção planejada. No entanto, é possível que as estruturas agramaticais que aparecem na fala não planejada sejam aquelas que normalmente (na sequüência natural) seriam aprendidas mais tarde. Adotado este tipo de ensino que inclui uma boa dose de gramática e que nem por isso deixa de ser comunicativo (cf., p.ex. Silva, 1989), quando algumas estruturas marcadas não foram ensinadas ainda, os aprendizes parecem seguir a estratégia: "Se não foi ensinado, é melhor pensar que é errado" (Ellis, 1994). Em outras palavras, a produção dos alunos se torna mais correta, porque permite uma atenção consciente à estrutura em uso, sua análise e a consequiente elaboração das hipóteses da representação mental mais adequada. É óbvio que estamos generalizando, visto que na aquisição da segunda língua também entram os fatores individuais dos aprendizes e, em última conta, a produção dependerá, entre outras coisas, do grau da sensibilidade gramatical do aluno, principalmente quando o curso de português não prevê a organização explícita da gramática. Almeida Filho (1996) relata o caso de uma aluna hispanofalante que "cria" no seu discurso a forma "européios" inexistente em português e sem explicação para o autor. Dentro do nosso raciocínio, a forma se explica facilmente como uma overgeneralization intralingüística. $\mathrm{O}$ fato de esse tipo de overgeneralization existir na produção da aluna mostra que ela mantém a distância psicolingüística, está atenta às regras periféricas, percebe que "existe algo diferente" na língua-alvo em comparação com a materna. A diferença europea (esp.)/ européia (port.) a leva a postular a regra overgeneralizada para o (plural) masculino em português. Em todo caso, como argumentam Eckmann et al. (1988), ensinar a gramática no momento certo pode acelerar o percurso do caminho da interlíngua e, acrescentaríamos, no caso das nossas duas línguas, atrasar a tal da "fossilização", evitando aquilo que chamamos de "portunhol", levando o desenvolvimento da competência da $\mathrm{L}_{2}$ ao ponto mais próximo da competência dos falantes nativos.

Acreditamos que o acima exposto permite explicar do por que, na Universidade Federal do Paraná, uma das condiçōes desejáveis e, no caso do ensino de português para hispanofalantes, a condição necessária é o co- 
nhecimento, pelo menos metalingüístico, por parte do professor, da língua materna dos alunos. Mas, mesmo assim, o professor continuaria se apoiando em muito nas suas próprias intuições. Isso, porque existem muito poucos estudos comparativos entre o português e o espanhol - claro que esse fato reflete também a falta de boas descrições do português brasileiro e do("s") espanhol ("espanóis"), principalmente o("s") falado("s") nos países da América. Não estamos pregando aqui a volta aos estudos contrastivos do tipo estruturalista/behaviourista. A verdade é que o aprendiz, para progredir e ao progredir na aquisição da $\mathrm{L}_{2}$, estabelece comparações entre as $\mathrm{L}_{1}$ e $\mathrm{L}_{2}$, como estabelece comparações entre a realidade da comunidade da sua língua materna e a da língua que está aprendendo (cf. Chacon, 1993). E também é verdade que um bom professor recorre às comparações, mesmo que estas sejam baseadas tão somente nas suas intuições. Assim, precisamos dessas pesquisas para identificar, entre outras coisas, por exemplo, as regras periféricas, as estruturas marcadas, as quais, como mostramos, desempenham um papel quase decisivo na aquisição do português/L2 pelos hispanofalantes. É preciso que essas pesquisas sejam bem delineadas e planejadas, pois terão inúmeras implicações teóricas e práticas. Só a título de ilustração esboçaremos grosso modo algumas dessas linhas de pesquisà:

\section{Fonética/fonologia}

Trata-se de comparar os sistemas fonéticos e fonológicos das duas línguas e descrever as regras, analisando e comparando-as. Não basta só commparar, porque isso leva às constatações do tipo: "No português têm sete fonemas vogais orais e no espanhol cinco, portanto vamos aos exercícios" (cf., p.ex., Lombello \& Baleeiro, 1983, que oferece exercícios de audição e distinção fonológica absolutamente inacessíveis aos alunos nesse estágio). As regras fonológicas não analisadas - $e$ "fossilizadas" - pelo aprendiz levam às produções do tipo que observamos em uma esteticista chilena, vinte anos no Brasil, que alegremente massageava ora o "queixo" ora o "queijo" do freguês ou em uma argentina que insistia em pegar o "chatinho" (jatinho!).

\section{Morfossintaxe}

Há toda uma gama de pontos a serem estudados e comparados: as posições sujeito/objeto, advérbios, pronomes, formas verbais, inclusive como as de: 
Tengo leidos dos capítulos del libro.

Já li dois capitulos do livro.

\section{Léxico}

Na verdade, é o assunto mais "óbvio": lembremos da "ingenuidade" a respeito da natureza de uma língua que ainda impera entre muitos dos professores de línguas estrangeiras, reduzindo-se, com isso, o problema à confecção de inúmeras listas de "falsos amigos". Este é o nível mais investigado (em espanhol até pela própria tradição filológica), mas que está longe de ser esgotado. Só para ilustrar:

La inversión de valores exige responsabilidad.

$O$ investimento/ a inversão de valores exige responsabilidade. (Em português há duas possibilidades da interpretação da palavra "inversión", que dependerá do contexto).

\section{Semântica}

O trabalho com a semântica pressupõe a sintaxe. Trata-se, aqui, de estudar os significados das sentenças e dos elementos que as compõem. Para exemplificar:

Temos chegado tarde todos os dias.

*Temos chegado tarde hoje./ Hemos llegado tarde hoy.

A tarefa da semântica, neste caso, é a de explicar (insistimos: não de descrever apenas) os significados dos tempos verbais formalmente semelhantes (que incluirão os conceitos de tempo e aspecto) e explicar também sua co-ocorrência com os adverbios temporais.

Texto

Neste nível, devemos estudar a estruturação dos diferentes tipos de texto nas duas línguas e também comparar a "macroestrutura" (ou o estilo cultural?) 
textual, que intuitivamente sabemos ser diferente (praticamente qualquer tipo de texto em espanhol "dá muitas voltas" para dizer o que quer dizer, enquanto um texto em português é "mais direto" na sua argumentação). Não existem pesquisas desse tipo, que poderiam contribuir muito para a metodologia do ensino de leitura (compreensão, interpretação) e de produção de textos.

Sociopragmática

Aqui, a situação se complica muito porque, tratando-se das línguas faladas em um bom número de países, além das variedades sociais e atitudes de ordem psicopragmática, temos que levar em conta as variedades regionais e 0 problema das variantes a serem ensinadas. As pesquisas nesta área (como em outras) permitiriam "recortar" e sistematizar o necessário para programar os conteúdos e confeccionar melhores materiais didáticos.

\section{Psicolingüística}

Muito pouco sabemos, por exemplo, de como e em que ordem ocorre a aquisição dos elementos morfológicos, estruturas sintáticas, significados lexicais e sentenciais em português e espanhol como línguas maternas para podermos conjeturar qual seria a seqüência mais adequada da apresentação da gramática nas aulas dessas línguas como segundas.

Mas há ainda um outro lado da medalha. Sabemos que ser falante competente de uma língua é ser membro ou, ao menos, identificar-se com os membros da comunidade que fala esta língua. Em outras palavras, tratando-se de uma segunda língua, seu aprendiz teria que ter uma motivação integrativa e não (apenas) a instrumental (Gardener; Lambert, 1972). Aqui vem o exemplo eloqüente, ao nosso ver, de três irmãos chilenos que há 22 anos vieram ao Brasil, com as idades entre 17 e 23 anos, hoje todos casados com brasileiros e tendo filhos brasileiros. O mais velho se formou em engenharia no Chile (considera 0 ensino naquele país muito superior ao brasileiro), é autônomo, não se naturalizou, até hoje fala "portunhol". A irmã do meio tem curso secundário, é pequena empresária, tampouco se naturalizou, sua competência do português é mais para o "espaguês" do que para o "portunhol". A irmã caçula fez o curso superior no Brasil, hoje é funcionária pública, portanto brasileira naturalizada, seu português é muito próximo ao de falantes nativos. E será que sabemos algo das motivações que movem os nossos alunos? Será que sabemos que tipo de atitudes eles têm em relação tanto de sua língua materna, o espanhol, como em relação ao português? 
Assim, no caso do ensino do português/L2, a prática certamente precede a pesquisa e a teoria (Matos; 1989). Em outras palavras, o professor de português/L2 continua, de certo modo, trabalhando de modo "artesanal", intuitivo. Para começar a mudar essa situação, que, ao nosso ver, não é desejável, a Universidade Federal do Paraná deu alguns passos em direção à formação daquele professor "consciente" que almejamos ter. Em 1994, foi promovido o curso de extensão Português: Língua Estrangeira para capacitar professores já formados e alunos dos últimos períodos da Licenciatura em Português + Língua Estrangeira a atuarem como professores de português/ $/ \mathrm{L}_{2}$. O curso incluiu os módulos de Aquisição de Segunda Língua, Metodologias de Ensino de Línguas Estrangeiras e módulos específicos de Fonética/Fonologia, Morfologia, Sintaxe, Semântica/Pragmática, Compreensão/Produção de Textos em língua estrangeira do domínio do professor, isto é, a língua materna dos alunos deste professor, sempre em comparação com o português. Alguns dos participantes desse curso atuam hoje no Curso de Português para Estrangeiros do Centro de Línguas, criado em 1995. Estamos fazendo os primeiros "ensaios" no sentido de desenvolver pesquisas comparadas dentro do nosso curso de Mestrado em Letras, com algumas dissertações já defendidas e outras em andamento, abordando alguns problemas teóricos e apontando para os procedimentos práticos de ensino. Além disso, para atingir os objetivos que aqui discutimos, o nosso programa de atuação prevê a implementação de convênios com universidades dos países da América Latina, visando a realização de projetos de pesquisa conjuntos, a elaboração de materiais didáticos e a formação/capacitação/atualização de professores de espanhol e de português como segundas línguas.

\section{RESUMO}

Sabe-se que o português e o espanhol são línguas próximas, transparentes, embora essa transparência não seja simétrica. $O$ resultado dessa proximidade é o tristemente famoso "portunhol" dos aprendizes.

A problemática intercultural, sendo uma questão muito complexa, exige a busca de novos rumos para o ensino de línguas. Este trabalho discute o perfil acadêmico do professor de português $/ \mathrm{L}_{2}$, reflete sobre as especificidades de trabalho com alunos hispanofalantes e defende a urgência de pesquisas comparadas.

Palavras-chave: Ensino de Português/L2; Ensino de Linguas estrangeiras; Aquisição de segundas linguas. 


\section{RESUMEN}

Como se sabe, el portugués y el español son lenguas próximas, transparentes, aunque esta transparencia no sea simétrica. El resultado de esta proximidad es el tristemente famoso "portuñol" de los aprendices.

La problemática intercultural, siendo una cuestión muy compleja, exige la búsqueda de rumbos nuevos en la enseñanza de lenguas. Este trabajo discute el perfil académico del profesor de portugués/ $\mathrm{L}_{2}$, reflexiona sobre los problemas específicos de trabajo com alumnos hipano-hablantes y defiende la urgencia de investigaciones comparadas.

\section{REFERÊNCIAS BIBLIOGRÁFICAS}

ALMEIDA Filho, J.C. Uma metodologia especifica para o ensino de línguas próximas. A pontamentos do Curso ministrado durante o 4. Congresso Internacional do Ensino de Português como Língua Estrangeira. 21 a 25 de outubro, UNAM, México, 1996.

CANALE, M. From communicative competence to communicative language pedagogy. In: J.Richards; R.Schmidt (orgs.). Language and communication. Longman, 1983.

CHACON, L. Reflexões sobre o ensino/aprendizagem do português do Brasil para estudantes universitários estrangeiros. Trabalhos em Lingüística Aplicada 22, 55 62, 1993.

ECKMAN, F., L.Bell; D.Nelson. On the generalization of relative clause instructionin the acquisition of English as a second language. Applied Linguistics 9, 1-20, 1988.

ELLIS, R. The study of second language acquisition. Oxford: Oxford University Press, 1994.

GARDNER, R.; W.Lambert. Attitudes and motivation in second language learning. Rowley, Mass: Newbury House, 1972.

KADIA, $K$. The effect of formal instruction on monitored and spontaneous naturalistic interlanguage performance. TESOL Quarterly 22, 509-515, 1988.

LOMBELlO, L.C.; BALEEIRO. M. de A. Português para falantes de espanhol. Campinas, UNICAMP/FUNCAMP/MEC, 1983.

MATOS, F.G.de. Quando a prática precede a teoria: a criação do PBE. $l n$; J.C.P. de ALMEIDA FILHO; L.C.LOMBELLO (Orgs.). $O$ ensino de português para estrangeiros. Campinas, Pontes, 11-18, 1989.

PICA, T. Adult acquisition of english as a second language under different conditions of exposure. Language Learning 33, 465-497, 1983.

.The selective impact of instruction on second language acquisition. Applied Linguistics 6, 214-222, 1985. 
SILVA, H.M.da. Gramática y metodología comunicativas: Revisión y análisis. Estudios de Línguíística Aplicada, año 7, n. 9, 46-68, 1989.

SPADA, N. The interaction between types of content and type of instruction: some effects on the L2 proficiency of adult learners. Studies in Second Language Acquisition 8, 181-199, 1986. 